\title{
Educação (bildung) enquanto verniz: crítica ao Estado e psicofisiologia
}

Wilson Antonio Frezzatti Jr.

Professor associado da Universidade Estadual do Oeste do Paraná

\section{RESUMO}

Nietzsche frequentemente considera que a formação (Bildung) não é profunda, sendo apenas uma camada superficial que adorna. Procuramos mostrar neste artigo dois aspectos dessa crítica: a falsa formação que amansa o animal homem e o transforma em um cidadão obediente; e a impossibilidade de se modificar o homem por meio da educação. Propomos que esse segundo aspecto é resultado da leitura nietzschiana da psicofisiologia francesa do século XIX, principalmente Théodule Ribot.

Palavras-chave: educação; Estado; psicofisiologia.

\begin{abstract}
Nietzsche often asserts that the education (Bildung) is not deep, because it is only a superficial layer that adorns. This article presents two aspects of this critique: the false education that tames the human animal and turns him into an obedient citizen; and, the impossibility of changing the man by education. We propose that this second aspect is a result of Nietzsche's readings of French nineteenth-century psychophysiology, mainly Théodule Ribot.
\end{abstract}

Keywords: education; State; Psychophysiology. 
concepção de que a formação (Bildung) é apenas um verniz,
ou seja, uma camada superficial que recobre o homem, não o
atingindo de modo profundo, aparece, ao menos, associada a
duas perspectivas diferentes na obra do filósofo alemão Friedrich Nietzsche. Uma delas refere-se à falsa formação, aquela que é considerada capaz de melhorar o homem, mas que apenas o torna um animal de rebanho, e pode aparecer, nos textos nietzschianos, ligada à crítica ao Estado. A outra perspectiva considera que o processo formativo não pode efetivamente modificar um indivíduo, somente produz características aparentes. Neste artigo, apresentaremos essas duas perspectivas e mostraremos que a segunda talvez seja resultado das leituras nietzschianas da psicologia, da fisiologia e da biologia do século XIX.

\section{A falsa formação (Bildung) e o Estado}

Estado e cultura (Kultur), para Nietzsche, são antagônicos ${ }^{1}$. Há vários excertos nos quais esse antagonismo está explícito, por exemplo: “quantos 'Reiche alemães' não valem por um único Goethe! ... Todos os grandes períodos da cultura [Cultur] foram, politicamente, períodos pobres" (Fragmento póstumo 19 [11] setembro 1888); e, em GD/CI “O que falta aos alemães" $§ 4^{2}$, lemos:

1 Para os sentidos de cultura (Cultur ou Kultur), de Formação (Bildung) e de Civilização (Civilisation ou Zivilisation) em Nietzsche, cf. Frezzatti 2006a, p. 66-142. Também sobre o conceito de Bildung, cf. Weber 2011, p. 35-57.

2 Adotamos, para a citação das obras de Nietzsche, a convenção proposta pelos Cadernos Nietzsche, baseada na edição Colli/Montinari das obras completas do filósofo. As siglas são as seguintes: DS/Co. Ext. I, Considerações Extemporâneas I: David Strauss: o devoto e o escritor; EH/EH, Ecce homo; FG/GC, A gaia ciência; GD/CI, Crepúsculo dos idolos; HL/Co. Ext. II, Considerações Extemporâneas II: Da utilidade e desvantagem da história para a vida; JGB/BM, Além de bem e mal; MA I/HH I, Humano, demasiado humano; SE/Co. Ext. III, Considerações Extemporâneas III: Schopenhauer educador; Za/ZA, Assim falava Zaratustra. Na citação, o algarismo arábico indica o aforismo ou o parágrafo; no caso de GD/CI, o algarismo arábico, que se segue ao título do capítulo, indica o aforismo. Para os fragmentos póstumos, os números arábicos indicam o fragmento póstumo e são acrescidos da data na qual o fragmento foi escrito, de acordo com a edição Kritische Studienausgabe (KSA). Para as cartas, indicaremos "Briefe" acompanhada do volume e da página. 
A cultura $[$ Cultur $]$ e o Estado - que não nos enganemos quanto a isso - são antagonistas: o "Estado Cultural" ["Cultur-Staat"] é apenas uma idéia moderna. Cada um deles vive do outro, cada um prospera à custa do outro. Todos os grandes tempo da cultura [Cultur] são tempos de decadência política: o que é grande no sentido da cultura [Cultur] sempre foi apolítico, mesmo antipolítico.

O que caracteriza o Estado - especialmente o Estado unificado Alemão - é a formação de funcionários públicos e de técnicos ou a instrução [Unterrricht], e não a cultura. O Estado é, para Nietzsche, o novo ídolo que toma o lugar de Deus: "Olhai esses supérfluos! Roubam para si as obras dos inventores e os tesouros dos sábios; formação [Bildung] chamam a seus furtos - e tudo se torna, neles, em doença e adversidade! Olhai esses supérfluos! Estão sempre enfermos, vomitam fel e lhe chamam 'jornal'. Devoram-se uns aos outros e não podem, sequer, digerir-se" (Za/ZA I "Do novo ídolo"). Essa formação é subordinada ao Estado, sua figura central é o erudito (Gelerhte), quem valoriza o conhecimento dos livros e despreza a vida $^{3}$, e sua divulgação se faz pelos jornais, que já trazem pensamentos prontos para seus leitores. Para Nietzsche, a cultura (Kultur) assim produzida é, na verdade, entretenimento e mercadoria, não é expressão da potencialidade criativa humana.

A formação tomada a cargo pelo Estado, segundo o filósofo alemão, não é apenas um arremedo e uma subversão das metas de uma formação que eleva o homem, ela também é superficial. Ao visitar a terra da formação (Lande der Bildung), espantado, Zaratustra vê seus habitantes manchados de tinta (o verniz da formação) ${ }^{4}$ e cercados de espelhos por todos os lados (a vaidade do homem de formação): “Todos os tempos e povos lançam variegados olhares através de vossos véus; todos os costumes e crenças falam, variegados, através de vossos gestos. Se alguém vos tirasse véus e

3 Cf., por exemplo, HL/Co. Ext. II (Da utilidade e desvantagem da história para a vida) e $\mathrm{SE} / \mathrm{Co}$. Ext. III $\S 8$ (Schopenhauer educador).

4 Em outros textos, Nietzsche também fala da formação (Bildung) como algo superficial; por exemplo: fragmento póstumo 2 [180] outono 1885/outono 1886) e $J G B / B M \S 208$. 
mantos e cores e gestos, sobraria o suficiente para assustar os pássaros [um fantasma]" (Za/ZA II "Do país da formação"). Enfim, a formação, tal qual se configura no Estado alemão, é apenas uma parvoíce e uma pavonada. Longe de defender essa formação, Nietzsche reclama da falta do homem de cultura (Kultur), do cultivado (Gebildete) (cf. fragmentos póstumos16 [11] outono 1883, 5 [81] verão 1886/outono 1887 e 9 [119] outono 1887).

Ao criticar a Bildung alemã, no sentido de formação ou educação, o filósofo alemão propõe uma nova formação. Nietzsche sempre foi um crítico feroz de sua época, considerada decadente e medíocre, incapaz de produzir uma grande cultura. Nesse contexto, a única coisa que a educação (Erziehung) e a formação (Bildung) podem fazer é encobrir - e não erradicar - a verdadeira compleição do indivíduo, ou seja, enganar "acerca da plebe herdada no corpo e na alma" (cf. $J G B / B M \S 264$ e 231).

\section{As propostas nietzschianas de formação e educação}

As críticas que Nietzsche faz à formação e à cultura alemãs não o impedem de propor ações para uma educação efetiva. O fragmento póstumo 9 [153] outono 1887, intitulado "Os fortes do amanhã", propõe o uso de certos comportamentos para elevar o homem: não devemos depender do acaso para a produção do homem forte, mas devemos produzi-lo através da educação. Uma educação que pense no futuro e não no presente: “A mediocridade crescente do ser humano é precisamente a força que nos impele a pensar na seleção [Züchtung] de uma raça [Rasse] mais forte: que encontraria seu excedente justamente em tudo aquilo que a espécie medíocre se enfraqueceria (vontade, responsabilidade, segurança de si, capacidade de estabelecer alvos para si)" (Fragmento póstumo 9 [153] outono 1887). Os meios utilizados para isso são: isolamento, exercício de valores inversos ao da mediocridade, pathos da distância. Os costumes de uma cultura elevada devem ser opostos ao da cultura vigente decadente.

A humanidade, segundo o filósofo alemão, sempre pôs ênfase naquilo que não era importante para a educação (Erziehung); na verdade, ao desprezar a vida, valorizou aquilo que a negava e desvalorizou o que lhe incrementava. Devemos nos preocupar com aquilo que a tradição considera 
ser pequenas coisas: alimentação, lugar, clima, lazer (cf. EH/EH "Por que sou tão esperto" $\S 10$ e fragmento póstumo 25 [1] dezembro 1888/início janeiro 1889). É necessário começar a reaprender e afastar os aspectos decadentes de nossa civilização ${ }^{5}$. Nietzsche, no fragmento póstumo 15 [4] verão/outono 1883), afirma, por meio da perspectiva de Zaratustra, que o homem deve voltar a ser um animal para não sentir o pensamento ou deve tornar-se além-do-homem. Nesse último caso, deve-se: Fazer uma seleção (Züchtung) por meio da escolha de lugar, dos deveres de cada sexo, de nutrição, etc; Romper com o passado: para construir uma nova cultura, o compromisso deve ser com o futuro; e, Não evitar o erro: ele é condição de vida (“representar tragédias na vida e tomá-las com prazer!").

Parece claro que todas essas condições, costumes e regras educativas são pensadas por Nietzsche como técnicas seletivas que propiciariam a elevação do homem e da cultura. Em outras palavras, teríamos uma ação direta da cultura e da educação sobre o que o homem pode tornar-se. Assim, a cultura é, ao mesmo tempo, promotora e resultado de um processo seletivo, cujo instrumento principal é a educação ${ }^{6}$.

É importante destacar que o período do qual extraímos as afirmações e citações acima é o mesmo do desenvolvimento da noção de vontade de potência (Wille zur Macht). Dessa forma, uma cultura, analogamente ao organismo vivo, é constituída por um conjunto de impulsos ou forças que lutam por mais potência ${ }^{7}$. As características de uma cultura são expressão de uma perspectiva determinada por uma hierarquia de impulsos: o impulso (ou conjunto de impulsos) que for mais potente se revela como essencial. A perspectiva impõe uma seleção enquanto estiver dominando: quer manter as

5 No fragmento póstumo 22 [10] setembro/outubro 1888, Nietzsche faz mais exigências profiláticas ou higiênicas: 1. Evitar todo contato com aqueles que persistirem no "cristianismo"; 2. Considerando que o "cristianismo" é sintoma de uma fraqueza nervosa, deve-se evitar que haja contaminação a partir desse rebanho; 3. A Bíblia deve ser considerada um livro perigoso: os muitos jovens, para lê-la, devem receber precauções; 4. Os padres devem ser considerados uma espécie de chandala (os impuros e os intocáveis do sistema de castas indiano); e 5. Purificar todos os lugares, as instituições e a educação (Erziehung) da "mancha dos padres".

6 Sobre a educação enquanto processo seletivo, cf. Frezzatti 2006a, p. 183-244.

7 Sobre vontade de potência, cf. Marton 2000, p.41-72 e Frezzatti 2006b, p. 66-68. 
condições de seu crescimento. A cultura, através de suas regras e educação, sintetiza a experiência contra as dificuldades que um povo enfrenta ${ }^{8}$. Para manter-se, a cultura, como qualquer organismo, deve saber se defender contra várias ações que se exercem sobre ela A educação é a responsável por transmitir e perpetuar a experiência sintetizada em regras pela cultura. Impulsos bem hierarquizados, portanto, devem ser produzidos por uma seleção, para que seja produzido um estilo, uma cultura ${ }^{9}$.

Assim, considerando os excertos acima, temos indicações que Nietzsche considera que fatores culturais, ou seja, a educação ou a formação podem alterar a configuração de impulsos ou a dinâmica impulsional de um organismo. Entretanto, o filósofo alemão aponta também no sentido contrário. Em JGB/BM $\S 264$, ao considerar a herança racial enquanto algo próximo a um atavismo, isto é, ao considerar que não é possível retirar do homem o que seus antepassados fizeram de forma mais persistente e prazerosa, afirma: “com ajuda da melhor educação [Erziehung] e da melhor formação [Bildung], consegue-se cabalmente apenas enganar acerca dessa herança". Recorrendo a Horácio ${ }^{10}$, Nietzsche diz que é inútil expulsar a natureza, pois ela sempre retorna. Em Ecce homo, "Por que sou tão sábio" § 8 , ao indicar sua capacidade de análise fisiológica ("denunciar o que há de mais íntimo em qualquer alma"), descreve-a como uma habilidade de descobrir, ao primeiro contato, "aquela imundície escondida no fundo de uma natureza, que vem talvez de um sangue podre, mas que a recobre o

80 processo que determina uma cultura em função das dificuldades encontradas é baseado na adaptação funcional de Roux (cf. Frezzatti 2001, p. 127-128). Nesse conceito do neolamarckista alemão, um estímulo externo, ao agir como fator de diferenciação de uma parte em luta com outras partes, produz uma nova estrutura. $\mathrm{O}$ funcionamento dessa parte passa a estar em dependência direta daquele estímulo: enquanto ele excitar a parte, ela se desenvolve; se ele se extinguir, a parte se atrofia. No processo descrito por Nietzsche em JGB/BM § 262, encontramos os mesmos elementos: a) O estímulo externo exercido pelas dificuldades impostas ao grupo: a busca de recursos e a luta contra os vizinhos; b) Esse estímulo produz uma característica específica do grupo da mesma maneira que produziria um novo órgão; e c) Com o arrefecimento do estímulo externo, o tipo dominante do grupo se dilui como um órgão atrofiado.

9 "Cultura [Kultur] é, sobretudo, unidade de estilo artístico [Einheit des künstlerischen Stiles] em todas as manifestações da vida de um povo" (DS/Co. Ext. I § 1).

10 "Ainda que expulses a natureza com o esteio, voltará sempre" (Horácio, Epistolas I, 10, 24). 
verniz da educação [Erziehung]". Aqui a educação é novamente considerada um véu enganador que encobre a verdadeira natureza. $\mathrm{O}$ homem apenas se torna o que ele é, apesar da educação (Erziehung), da instrução (Unterricht), do meio, do acaso e dos acidentes (cf. fragmento póstumo 14 [113] primavera 1888). Não se é livre para ser o que não se é ${ }^{11}$. A degeneração moral, por exemplo, não seria causa de doença, mas simplesmente um complexo de sintomas da degeneração impulsional (cf. fragmento póstumo 25 [1] dezembro 1888/início janeiro 1888).

A ideia que parece estar presente nesses textos é a de que condições que permitam o crescimento dos impulsos devem ser utilizadas e que aquela hierarquia que puder crescer será mantida (o "ser o que se é"). A hierarquia de impulsos que não puder crescer deve ser deixada para a decadência derradeira, eliminada por si só pela dispersão das forças. A seleção, portando, neste caso, parece ser a facilitação de crescimento para aquele conjunto de impulsos que, por sua própria configuração ou hierarquização, é passível de crescer, de ser aquilo que é, ou ainda de vir-a-ser cada vez mais potente. O que parece estabelecer, na formação do homem, um predomínio da configuração de impulsos independente da situação cultural, a qual teria apenas um papel secundário, ou seja, o de facilitar o crescimento. $\mathrm{O}$ "tornarse o que se é" nada mais seria do que o processo de aumento de potência de uma configuração de impulsos que atinge seu quantum máximo de potência.

\section{A formação como uma modalidade da hereditariedade: influência da psicofisiologia francesa \\ Queremos propor que a última perspectiva sobre a formação foi construída por Nietzsche a partir de suas leituras da psicofisiologia francesa, especialmente Théodule Ribot e sua Revue philosophique de la France et de l'étranger.}

$11 \mathrm{O}$ "como se chega a ser o que se é" ("wie man wird, was man ist"), subtítulo de Ecce homo, é a transformação em forma interrogativa do lema das Odes Píticas de Píndaro, que está na forma imperativa: "transforma-te no que és!" (cf. Larrosa 2002, p. 47-48). A frase aparece, nos escritos nietzschianos, pela primeira vez, em grego, no imperativo e em epígrafe, em um trabalho juvenil sobre Teógnis. É um dos lemas da terceira extemporânea (Schopenhauer como educador) e aparece, com certas modificações, em MAI/HHI § 263, FW/GC $§ 270$ e 335 e Za/ZA "O convalescente" e "A oferenda de mel”, além de ser tema de várias cartas, sem citar suas inúmeras variações. 
Théodule Ribot (1839-1916), considerado o fundador da psicologia francesa, não clinicava e não realizava experimentos em laboratório, mas foi a principal figura e o catalisador da criação da psicologia enquanto disciplina independente. Ribot foi o responsável, na França, pelo projeto de uma psicologia científica com caráter de disciplina axial para a discussão das questões humanas, livre da filosofia, ou seja, livre de questões metafísicas: buscava uma psicologia baseada na fisiologia, ou seja, uma psicofisiologia. É na Revue philosophique de la France et de l'étranger que grande e importante parte do debate ocorre. O periódico foi fundado por Ribot em 1876 para agregar as discussões em torno do estatuto da psicologia e suas relações com as ciências naturais (especialmente a fisiologia e o evolucionismo) e a filosofia, ou seja, para divulgar uma "nova psicologia" (positivista e científica) em substituição à "velha psicologia" (espiritualista e metafísica, isto é, "filosófica"). Esse projeto culminou com a criação, em 1888, da cátedra de "Psicologia experimental e comparada" no Collège de France, assumida pelo próprio Ribot. Esse fato é considerado o marco inaugural da psicologia científica francesa ${ }^{12}$.

Em Hereditariedade (Hérédité, 1873), Ribot defende que algumas formas sociais e culturais, instituições tais como família, soberania, castas, nobreza e educação, nada mais são do que extensões da transmissão

12 Não é fácil identificar com precisão o que Nietzsche efetivamente leu de Ribot e de seu periódico. Por outro lado, é inegável a presença nos textos nietzschianos de vários temas presentes naqueles escritos, as semelhanças são muitos grandes (cf. Frezzatti 2010). O filósofo alemão cita explicitamente o nome de Ribot apenas em duas cartas: uma para Paul Rée do início de agosto de 1877 e outra para Malwida von Meysenbug de 04 de agosto do mesmo ano. Nessas cartas, Nietzsche mostra conhecer o periódico e o elogia (Briefe 5, p. 266 e 268). Os livros de Ribot que Nietzsche pode ter conhecido, por leitura direta ou pelos resumos publicados na Revue, são os seguintes: A psicologia inglesa contemporânea (1870); A hereditariedade: estudo psicológico sobre seus fenômenos, suas leis, suas causas, suas conseqüências (1873); A psicologia alemã contemporânea (1879); As doenças da memória (1881); As doenças da vontade (1883) e As doenças da personalidade (1885). O que temos de certo é que Nietzsche conhecia a Revue philosophique e que tinha em sua biblioteca (e provavemente leu) inúmeros livros dos principais autores que freqüentavam as páginas da revista, entre eles: Ribot, Alexander Bain, Alexander Herzen (filho), Alfred Espinas, Alfred Fouillé, A. B. Morel, Louis Büchner, Thomas Carlyle, Charles Féré, Charles Richet, E. Beneke, Eduard von Hartmann, Émile Durkheim, Eugen Dühring, Gustav Theodor Fechner, Francis Galton, Friedrich Albert Lange, Georg Heinrich Schneider, Hermann von Helmholtz, Gustave Le Bon, Herbert Spencer, Hyppolite Taine, Franz Brentano, J. Delboeuf, J. Hughlings Jackson, Jean-Marie Guyau, Johannes von Kries, Émile Littré, Cesare Lombrozo, Karl Wilhelm von Naegeli, Paolo Mantegazza, Paul Rée e Wilhelm Wundt. 
hereditária natural em uma configuração mais complexa. A hereditariedade, segundo o psicólogo francês (Ribot 1873, p. 501-502), apresenta-se de duas formas: natural (fisiológica e psicológica) e instituída, sendo que a segunda provém da primeira. Todos os povos, especialmente em suas fases mais primitivas e não civilizadas, tiveram, ao menos de uma forma vaga, uma crença na transmissão hereditária, inclusive na hereditariedade institucional, sendo que esta foi desenvolvida e reforçada por razões sócio-políticas e mesmo por preconceitos. As características da hereditariedade estão nas instituições sociais: necessidade, conservação e estabilidade. Vejamos, como exemplo, o caso da nobreza.

A nobreza (noblesse) teria causas naturais, nascendo da desigualdade primitiva dos talentos e das características (cf. Ribot 1873, p. 513-523). Na história, a nobreza apresentou-se de várias formas, mas sempre como uma seleção voluntária e consciente, fixada por instituições. Ou melhor, ela própria pretendia que as coisas se passassem dessa forma. De qualquer maneira, a instituição aristocrática assenta-se na hereditariedade, na seleção de certas características. Surge de vários modos (conquista, recompensa por ação espetacular, etc.), mas sempre se baseia na hereditariedade: a idéia (verdadeira ou falsa) de possuir um mérito acima do comum e de que ele é transmissível. Ela deve se perpetuar e proteger a tradição, manter-se pura, sendo garantia da estabilidade do Estado. De um ponto de vista ideal, segundo Ribot, a instituição da nobreza é excelente, porque busca preservar os bons resultados ("as plantas raras") de um processo de seleção rigoroso (educação). Mas, como diz o próprio psicólogo: 'Mais cela n' est beau qu' en rêve" (Ribot 1873, p. 517). O motivo está numa idéia própria do positivismo: a nobreza que pretende ser uma elite, na verdade, só o foi em um sentido muito estrito, no da virtude guerreira, pois ela nasceu na época da adolescência dos povos, na qual a imaginação tem como ideal apenas o heroísmo - a única virtude é a honra e a única ocupação, a guerra. Além disso, os processos seletivos nunca foram completos e foram mal aplicados; e, se a seleção é imperfeita, a transmissão hereditária é falha. Porém, o mais 
importante é que as aristocracias, como todos os corpos fechados, não assimila o novo e sofre a degradação natural ${ }^{13}$.

Esse é o aspecto que queremos destacar: a hereditariedade, para Ribot, embora seja uma das principais leis da vida, não é algo que seja infalível. Em condições ideais, ela produz a repetição contínua das mesmas propriedades, mas, nas condições extremamente complexas dos seres vivos, nas quais várias leis se sobrepõem, a semelhança é apenas aproximativa. A degradação das características transmitidas ocorre porque há uma "luta pela existência" da hereditariedade com as forças contrárias em cada geração. Mesmo que a característica se transmita, há perdas (cf. Ribot 1873, p. 520). Essa degradação, em um primeiro momento provocada pelo enfraquecimento da hereditariedade, e depois transmitida ela própria pela hereditariedade, aniquila, após algum tempo, os organismos fechados neles mesmos. Enfim, a nobreza - como toda característica natural - não é eterna, mas transitória porque entra em decadência, ou seja, a nobreza é um fato natural. O mesmo ocorre com a educação.

Em “A hereditariedade e a educação" seção II do capítulo III da quarta parte de Hérédité (cf. Ribot 1873, p. 482-488), Ribot diz que a influência da educação é análoga ao do clima, do solo, do ar e do regime alimentar, ou seja, produz sensações inconscientes que se tornam hábitos. Mas, porque é um meio moral, é heterogêneo, mutante e complexo em alto grau: pais, professores, costumes, crenças religiosas, conversações e outras percepções indefinidas. O produto da educação é um conjunto de hábitos, uma segunda natureza. Entretanto, segundo Ribot, alguns exageram na importância dada à educação, como Helvetius: "todos os homens nascem iguais e com aptidões iguais, apenas a educação faz a diferença". Efetivamente, a educação nunca é absoluta e sua ação é eficaz apenas sobre as naturezas medianas. A biografia da maioria dos homens célebres mostra que a influência do processo educativo sobre eles é quase nula.

13 A nobreza, além de propiciar um sentimento de superioridade, oferece a oportunidade de grandes feitos: auto-sacrifício por algo maior (heroísmo, cavalheirismo, etc.). Mas uma sociedade que acredita na hereditariedade das virtudes também acredita na hereditariedade dos vícios, o que gera resultados assustadores como as raças malditas, as castas impuras e a punição dos descendentes por atos de seus ascendentes (cf. Ribot 1873, p. 520-523). 
Não é raro encontrar, em nossos dias, nas famílias altamente colocadas, mesmo principescas, homens que a educação culta [savante] recobre, mas não penetra: ela é apenas um brilhante verniz, que, ao primeiro golpe, cai em lascas, e, então, a verdadeira natureza, isto é, a bruta, aparece com seus instintos selvagens e seus apetites desenfreados; de um só golpe, ela quebra todos os liames que a civilização o envolveu e se reencontra na barbárie como em seu país natal. (Ribot 1873, p. 488)

Eis, novamente, a ideia da educação como um verniz, que recobre de modo frágil uma verdadeira natureza. Em conseqüência, não se deve superestimar o papel da educação. Na conclusão de Hereditariedade, o psicólogo francês tenta responder às esperanças de Spurzheim, no início do século XIX, do homem poder criar a si próprio (cf. idem p. 538-539). Ribot é cauteloso por não conhecermos todas as leis envolvidas no processo de hereditariedade, mas acredita que uma seleção dirigida, aplicada durante longo tempo, daria bons resultados. No entanto, esses resultados não poderiam ser abandonados a eles mesmos, pois, pelo enfraquecimento natural da hereditariedade, haveria o "retorno ao tipo original". Há no indivíduo uma luta entre a hereditariedade das características naturais e a hereditariedade das características adquiridas. Nessa luta, a natureza vence se a técnica não a enfrentar. Esse é o caso da educação, que, para Ribot e também para Nietzsche, é um processo seletivo. A educação age sobre as faculdades mentais da mesma maneira que os criadores atuam sobre os animais e as plantas (cf. idem, p. 402). E, se a técnica for constante (educação, meio moral, etc.), as características adquiridas se fixam e estabelece-se em nossa constituição física uma segunda natureza tão ligada à primeira que não podemos mais distingui-las.

\section{Considerações finais}

Podemos perceber diferenças muito grandes em relação a Nietzsche no que apresentamos acima acerca do pensamento de Ribot sobre as instituições humanas: hereditariedade, auto-sacrifício pelo coletivo e nobreza como 
preconceito. Porém, se trocarmos as causas naturais pela dinâmica dos impulsos (fisiologia nietzschiana) e considerarmos que, por vezes, o filósofo alemão trabalha implicitamente com a noção de hereditariedade, as semelhanças são também grandes: a origem e a decadência da nobreza, o pathos da distância, o caráter guerreiro da aristocracia, a cultura como produto de processos vitais e o processo seletivo. O "retorno ao tipo original" e a produção de "segundas naturezas" são típicos da físiologia e da biologia da segunda metade do século XIX, e incorporam fortemente elementos evolucionistas ou de teorias do desenvolvimento e diferenciação orgânicos. Essas noções aparecem de modo importante no texto nietzschiano $^{14}$.

Nietzsche não transpôs simplesmente para sua filosofia as noções científicas encontradas em suas leituras. Ele as digeriu e as transformou em conceitos filosóficos próprios às suas reflexões. O mundo, para Nietzsche, é um imenso laboratório de experiências, em que certas coisas têm sucesso, outras fracassam, e falta uma ordem ou uma lógica entre elas. Não há uma ordenação visando a um fim, à perfeição humana. A vontade de potência e a luta dos impulsos por mais potência fazem parte da tentativa nietzschiana de produzir essa interpretação sobre a realidade (Wirklichkeit). A educação não fica fora dessa visão de mundo que valoriza as possibilidades criativas humanas. Esse aspecto, para nós, é fundamental para elucidar o pensamento do filósofo alemão: não colocar a educação nietzschiana na perspectiva da dinâmica agonística dos impulsos provoca equívocos como, por exemplo, confundir as ideias do filósofo alemão com aquelas vigentes em sua época nos meios intelectuais da Alemanha. Ao se considerar as principais características da proposta nietzschiana de educação (a busca da elevação da cultura; o desprezo pela especialização, pela erudição e pela cultura livresca; 14 Sobre a noção nietzschiana de segunda natureza, cf. Considerações Extemporâneas II: Da utilidade e desvantagem da história para a vida (HL/Co. Ext. II), § 3. Nesse parágrafo, Nietzsche afirma que a primeira natureza é resultado da herança do que é inato e do que é adquirido. Por meio de uma nova e rigorosa disciplina, que implanta um novo hábito e novos instintos, ela pode ser sobrepujada. Os novos hábitos e instintos formam uma segunda natureza que debilita a primeira, mas não há garantia de que a nova natureza substitua a antiga, pois ela geralmente é mais fraca. Entretanto, caso isso ocorra, a segunda natureza se transforma em primeira. Esse processo é contínuo: toda primeira natureza já foi segunda, e toda nova natureza que aniquila a antiga se torna primeira. 
a preocupação com a decadência do Geist alemão, com a massificação e com o nivelamento da cultura) e algumas idéias importantes para a reflexão nietzschiana acerca da cultura (a oposição entre cultura e civilização, a hierarquia, a luta por mais potência, os valores "nobres" ou "aristocráticos", a crítica à igualdade dos homens), poder-se-ia pensar que o filósofo alemão fizesse parte ou fosse porta-voz de uma elite ciosa em salvaguardar seus preciosos valores tradicionais. Nietzsche, entretanto, buscava criar uma filosofia que produzisse novas noções - de educação inclusive - que pudessem propiciar que a potência humana se manifestasse em suas múltiplas formas.

\section{Referências Bibliográficas}

FREZZATTI Jr., Wilson A. Nietzssche contra Darwin. São Paulo/Ijuí: Discurso/UNIJUÍ, 2001.

- A fisiologia de Nietzsche: a superação da dualidade cultura/biologia. Ijuí: UNIJUÍ, 2006a.

A psicologia de Nietzsche: afirmação e negação da vida como sintomas de saúde e doença. In: SOUZA, Eliane C. de; CRAIA, Eladio C. P. Ressonâncias filosóficas: entre o pensamento e a ação. Cascavel: EDUNIOESTE, 2006b. p. 65-82

. Nietzsche e Théodule Ribot: Psicologia e superação da metafísica.

Natureza bumana, São Paulo, 12 (2), 2010. Disponível em $<$ http://pepsic.bvsalud.org/scielo.php?script=sci_arttext\&pid=S1517-

24302010000200007\&lng=pt\&nrm=iso $>$

LARROSA, J. Nietz̧sche \& a educação. Tradução: S. G. da Veiga. Belo Horizonte: Autêntica, 2002.

MARTON, S. Nieţsche: das forças cósmicas aos valores bumanos. $2^{\mathrm{a}}$ ed. Belo Horizonte: UFMG, 2000.

NIETZSCHE, F. W. Sämtliche Briefe. Kritische Studienausgab. Berlin/New York: Walter de Gruyter, 1986. 8 Bd - Sämtliche Werke. Kritische Studienausgabe (KSA). G. Colli und M. Montinari (Hg). Berlin: Walter de Gruyter, 1999. 15 Bd 
RIBOT, T. L' hérédité: Étude psychologique sur ses phénomènes, ses lois, ses causes, ses conséquences. Paris: Librairie Philosophique de Ladrange, 1873.

WEBER, J. F. Formação (Bildung), educaşão e experimentação em Niețsche. Londrina: EDUEL, 2011. 